\title{
Study of the Effect of Hydrogen charging on the tensile properties and microstructure of four variant heat treatments of nickel alloy $\mathbf{7 1 8}$
}

DOI:

10.1016/j.jhydene.2017.02.149

\section{Document Version}

Accepted author manuscript

Link to publication record in Manchester Research Explorer

Citation for published version (APA):

Demetriou, V., Robson, J., Preuss, M., \& Morana, R. (2017). Study of the Effect of Hydrogen charging on the tensile properties and microstructure of four variant heat treatments of nickel alloy 718 . International Journal of Hydrogen Energy. https://doi.org/10.1016/j.ijhydene.2017.02.149

Published in:

International Journal of Hydrogen Energy

\section{Citing this paper}

Please note that where the full-text provided on Manchester Research Explorer is the Author Accepted Manuscript or Proof version this may differ from the final Published version. If citing, it is advised that you check and use the publisher's definitive version.

\section{General rights}

Copyright and moral rights for the publications made accessible in the Research Explorer are retained by the authors and/or other copyright owners and it is a condition of accessing publications that users recognise and abide by the legal requirements associated with these rights.

\section{Takedown policy}

If you believe that this document breaches copyright please refer to the University of Manchester's Takedown Procedures [http://man.ac.uk/04Y6Bo] or contact uml.scholarlycommunications@manchester.ac.uk providing relevant details, so we can investigate your claim.

\section{OPEN ACCESS}




\title{
Study of the Effect of Hydrogen charging on the tensile properties and microstructure of four variant heat treatments of nickel alloy 718
}

\author{
Authors: V.Demetriou ${ }^{1,2}$, J. D. Robson ${ }^{1}$, M. Preuss ${ }^{1,2}$, R. Morana ${ }^{2,3}$ \\ School of Materials, University of Manchester ${ }^{1}$ \\ BP International Centre of Advanced Materials (ICAM) ${ }^{2}$ \\ BP Exploration \& Production ${ }^{3}$
}

Keywords: Alloy 718, Hydrogen Embrittlement, $\delta$ phase, fractography, SEM, Slip bands

\begin{abstract}
This study examined the hydrogen embrittlement sensitivity of nickel alloy 718 given four different heat treatments to obtain various microstructural states. The four heat treatments examined are the oil and gas 718 heat treatment, the aerospace 718 heat treatment, and two variant two-step heat treatments, with a difference in aging heat treatment named 718 low band and high band. Each heat treatment leads to differences in the precipitate morphologies of $\gamma^{\prime}, \gamma^{\prime \prime}$ and $\delta$ phases.

Material characterisation and fractography of the examined heat treatments were performed using a high resolution FEG SEM. Three specimens of each condition were pre-charged with hydrogen and tensile properties were compared with those of non-charged specimens. It was observed that hydrogen embrittlement was associated with intergranular and transgranular microcrack formation, leading to an intergranular brittle fracture. $\delta$ phase may assist the intergranular crack propagation, and this was shown to be particularly true when this phase is coarse enough to produce crack initiation, but this is not the only factor determining embrittlement. Other microstructural features play a role, as does the strength of the material. The aerospace heat treatment, which gives the highest strength and ductility in the uncharged state, shows the greatest reduction in properties with hydrogen charging.
\end{abstract}

\section{Introduction}

The precipitation hardening nickel base alloy UNS N07718 (known as Alloy 718) is extensively used by the oil and gas industry due to its exceptional mechanical and corrosion properties in sour service environments. According to API standard 6A718 [1], alloy 718 heat-treated for oil and gas application has a $0.2 \%$ proof stress up to $1000 \mathrm{MPa}(145 \mathrm{ksi})$. The strength of the nickel-iron-chromium alloy 718 is largely dependent on the precipitation of the $\left.\mathrm{L}_{2} \gamma^{\prime}-\mathrm{Ni}_{3}(\mathrm{Al}, \mathrm{Ti})\right)$ and $\mathrm{BCT} \gamma^{\prime \prime}-\mathrm{Ni}_{3} \mathrm{Nb}$ phases during heat treatment $[2,3]$. If the alloy is used above $\sim 650^{\circ} \mathrm{C}$, some of the $\gamma^{\prime \prime}$ precipitates may convert to the stable $\delta\left(\mathrm{Ni}_{3} \mathrm{Nb}\right)$ orthorhombic phase. The alloy, in its as-received condition, contains $\delta$ phase precipitates on some of the grain boundaries. A major part of the development effort with this alloy has been concerned with establishment of heat treatments for producing optimum properties. Moreover, the material is produced under the National Association of Corrosion Engineers (NACE) specification MR0175, which specifies the required heat treatment conditions and strength levels (the maximum hardness in the aged condition is limited to 40 Rockwell $\mathrm{C}$ for this application) to provide good service life in sour oilfield conditions [4].

However, an unfavourable combination of different parameters can degrade the toughness of the precipitation hardened nickel alloy 718. A fraction of the hydrogen atoms produced by several routes in the oilfield environment, (like chemical degradation, galvanic coupling, cathodic protection etc.) are absorbed by the material. This phenomenon might decrease the toughness of the metal, leading to crack propagation until failure occurs. In the past decades, 
several studies have been performed on alloy 718 with different experimental techniques, to examine the effect of hydrogen on the mechanical properties [5-10], the impact of hydrogen on the microstructure [11-15], and to evaluate the alloy's hydrogen trapping, diffusivity, solubility and permeability of the alloy [16-21]. Some of these studies have related the hydrogen embrittlement in alloy 718 with the collection of hydrogen by the intergranular $\delta$ $\left(\mathrm{Ni}_{3} \mathrm{Nb}\right)$ phase $[6,8,13]$. Investigators have concluded that the presence of intergranular $\delta$ provides easy routes for crack propagation in the alloy and also leads to severe degradation of toughness, mainly in the presence of hydrogen, causing hydrogen embrittlement $[2,6,8,13,15,22]$. Therefore, a new metallurgical state of alloy 718 should be designed to improve hydrogen embrittlement resistance at high strengths and resistance to crack failures like sulphide stress cracking (SSC) and stress corrosion cracking (SCC) in oil and gas conditions, since some microstructural features of alloy 718 might lead to a form of embrittlement.

Alloy 718 specimens that are hot worked below the $\delta$ solvus temperature of approximately $1000^{\circ} \mathrm{C}$, for example in the range of $927^{\circ} \mathrm{C}-982^{\circ} \mathrm{C}$, will usually contain the correct distribution of non-continuous intergranular $\delta$ phase. The suggested solution heat treatment to avoid $\delta$ phase is $1021^{\circ} \mathrm{C}-1052^{\circ} \mathrm{C}$ for 1 to 2.5 hours followed by air cool or quenching [1]. According to the same standard [1], the recommended heat treatment for the oil and gas 718 alloy is between $760^{\circ} \mathrm{C}-802^{\circ} \mathrm{C}$ for $6-8$ hours.

The oil and gas alloy 718 has a single step heat treatment, compared to the two-step aging heat treatment applied when 718 alloy is used for aerospace applications, where property requirements are different. The heat treatment for oil and gas applications is designed to address higher fracture toughness with adequate strength and corrosion resistance to hydrogen embrittlement and stress corrosion cracking [23,24]. On the other hand, $\delta$ phase is intentionally utilised in the 718 aerospace heat treatment (AER HT) in order to control grain size for improved fatigue strength $[25,26]$. The alloy is solution heat treated below $\delta$ solvus, followed by a two-step aging treatment to precipitation harden the material with $\gamma^{\prime}$ and $\gamma^{\prime \prime}$.

The aim of this work is to investigate the effect of cathodically charged hydrogen on the tensile properties of four variant heat treatments of alloy 718. The four heat treatments were: the oil and gas 718, the aerospace 718 heat treatment (HT), and two variant two step heat treatments, with a difference in aging heat treatment named 718 low band and high band HT. Material characterisation and fractography of the examined heat was performed using a highresolution field emission gun scanning electron microscopy (FEG SEM). Moreover, conclusions have been drawn concerning the cause and mechanism of failure in this alloy.

\section{Material and Experiments}

The chemical composition of alloy 718 is shown in Table 1. Cylindrical blanks of $10 \mathrm{~mm}$ in diameter and $100 \mathrm{~mm}$ in length were cut from the forged alloy using electrical discharge machining (EDM) at equal distances from the edge of the billet. The as-received condition of the 718 forging had undergone the two step aerospace (AER) HT, with a Vickers hardness of $438( \pm 5) \mathrm{HV}$ and a $0.2 \%$ yield strength and ultimate yield strength of $1114 \mathrm{MPa}$ and 1276 $\mathrm{MPa}$, respectively.

Table 1: Chemical composition of alloy 718 (wt.\%)

\begin{tabular}{|c|c|c|c|c|c|c|c|c|c|c|}
\hline \multicolumn{10}{|c|}{ Chemical composition of Inconel alloy 718, wt. \% } \\
\hline $\mathbf{N i}$ & $\mathbf{C r}$ & $\mathbf{F e}$ & $\mathbf{M o}$ & $\mathbf{N b}+\mathbf{T a}$ & $\mathbf{C u}$ & $\mathbf{T i}$ & $\mathbf{A l}$ & $\mathbf{M n}$ & $\mathbf{S i}$ & $\mathbf{S}$ \\
\hline 54.7 & 18.5 & 17.06 & 3.09 & 5.01 & 0.06 & 0.88 & 0.45 & 0.09 & 0.09 & 0.0003 \\
\hline $\mathbf{P}$ & $\mathbf{C}$ & $\mathbf{B}$ & $\mathbf{W}$ & $\mathbf{C o}$ & $\mathbf{T a}$ & $\mathbf{P b}$ & $\mathbf{M g}$ & $\mathbf{S e}$ & $\mathbf{B i}$ & $\mathbf{C a}$ \\
\hline 0.007 & 0.02 & 0.0039 & 0.02 & 0.01 & $<0.005$ & $<0.0005$ & $<0.006$ & $<0.0003$ & $<0.00003$ & $<0.003$ \\
\hline
\end{tabular}


The investigated heat treatments, low band (LB), high band (HB), and oil and gas (O\&G) were performed on the cylindrical 718 alloy blanks. The examined heat treatments are described in Table 2. An inert atmosphere argon tube furnace with a Newtronic Micro $96 \mathrm{TP}+$ temperature controller was used to perform the required solution annealing and aging treatments. Specimens were first solution annealed at $1040^{\circ} \mathrm{C}$ to dissolve all precipitates into solid solution and water quenched. Then, each aging treatment was performed on six blank specimens at the same time to grow uniform $\gamma^{\prime \prime}$ and $\gamma^{\prime}$ precipitates and to strengthen the alloy. After the age hardening process, all samples of the examined heat treatments were water quenched, and $10 \mathrm{~mm}$ slices were cut from one sample from each heat treatment for detailed material characterisation.

Table 2: The examined heat treatments of alloy 718

\begin{tabular}{|c|c|c|c|c|}
\hline \multirow[b]{2}{*}{$\begin{array}{l}\text { Heat } \\
\text { treatment } \\
\text { name }\end{array}$} & \multirow[b]{2}{*}{ Material } & \multicolumn{2}{|c|}{ Solution Annealing } & \multirow{2}{*}{$\begin{array}{c}\text { Age Hardening } \\
\text { Material Temperature }\left({ }^{\circ} \mathrm{C}\right) \text { and Time }\end{array}$} \\
\hline & & $\begin{array}{c}\text { Material } \\
\text { Temperature } \\
\left({ }^{\circ} \mathrm{C}\right)\end{array}$ & $\begin{array}{l}\text { Time } \\
\text { (Hr) }\end{array}$ & \\
\hline $\begin{array}{l}\text { Aerospace } \\
\text { (AER) }\end{array}$ & 718 & $927-1010$ & $1-2.5$ & $\begin{array}{l}718^{\circ} \mathrm{C} \text { for } 8 \text { hours, furnace cooled to } 621^{\circ} \mathrm{C} \\
\text { and held for total ageing time of } 18 \text { hours - } \\
\text { water quenched }\end{array}$ \\
\hline $\begin{array}{l}\text { Oil and gas } \\
(\mathrm{O} \& \mathrm{G})\end{array}$ & 718 & 1040 & 1 & $790^{\circ} \mathrm{C}$ for 7 hours - water quenched \\
\hline $\begin{array}{l}\text { Low band } \\
\quad(\mathrm{LB})\end{array}$ & 718 & 1040 & 1 & $\begin{array}{l}712^{\circ} \mathrm{C} \text { for } 4 \text { hours, furnace cool } 0.5^{\circ} \mathrm{C} \text { per } \\
\text { minute to } 616^{\circ} \mathrm{C} \text { and held for total ageing } \\
\text { time of } 12 \text { hours - water quenched }\end{array}$ \\
\hline $\begin{array}{l}\text { High band } \\
\text { (HB) }\end{array}$ & 718 & 1040 & 1 & $\begin{array}{l}715^{\circ} \mathrm{C} \text { for } 9 \text { hours, furnace cool } 0.5^{\circ} \mathrm{C} \text { per } \\
\text { minute to } 617^{\circ} \mathrm{C} \text { and held for total ageing } \\
\text { time of } 12 \text { hours - water quenched }\end{array}$ \\
\hline
\end{tabular}

Material characterisation and fractography were performed with a high resolution FEI Magellan FEG SEM. The accelerating voltage and beam current were set at $8 \mathrm{kV}$ and $0.8 \mathrm{nA}$ respectively. Working distance was set at 3 to $3.5 \mathrm{~mm}$. The backscattered electron mode was used for high resolution surface imaging to distinguish the different phases. Secondary electron mode was used for the fractography analysis of the failed tensile specimens. The grain size of the four conditions was determined by a linear intercept method using IMAGEJ image analysis software.

Energy dispersive x-ray spectroscopy (EDS) of the Magellan FEG SEM was used to perform semi-quantitative microanalysis of carbides. For these investigations, the accelerating voltage and beam current were set at $15 \mathrm{kV}$ and $0.8 \mathrm{nA}$, respectively. Working distance was $5 \mathrm{~mm}$.

The grinding and polishing procedures were carried out by hand using wet abrasive papers done to 4000 . Subsequently, a polishing cloth with $1 \mu \mathrm{m}$ diamond paste was used to polish the samples for around 3 minutes followed by $1 / 4$ micron diamond paste polishing for a minute. Finally, all samples were polished with an Oxide Polishing Suspensions (OPS) for 10 minutes to provide a scratch-free surface.

The examined samples were etched with a two-part nickel reagent etchant (contains $\mathrm{H}_{2} \mathrm{O}$, $\mathrm{HCl}, \mathrm{HNO}_{3}$ and Molybdic Acid) for 10 seconds. Afterwards, they were cleaned with water and dried with ethanol.

The hardness of all samples was measured with a Vickers hardness tester applying a load of $20 \mathrm{~kg}$. For each sample, an average hardness value from ten measurements was evaluated. 
For this investigation, standard "dogbone" shaped specimens from NACE TM0177 standard were used [27]. According to this standard, the $10 \mathrm{~mm}$ in diameter blank specimens were machined to the final dimensions for the test, having an overall length of $77.67 \mathrm{~mm}$ and M10 threaded ends. The gauge length was $25.4 \mathrm{~mm}$ with a diameter of $3.81 \mathrm{~mm}$.

An Instron 5569 system equipped with a $50 \mathrm{kN}$ load cell and a BlueHill data acquisition software were used to perform the uniaxial tensile tests, using an initial strain rate of $3.33 \times 10^{-}$ $4 /$ s. Six samples of each heat treatment were tested at room temperature $\left(\sim 20^{\circ} \mathrm{C}\right)$; three specimens of each metallurgical state were cathodically pre-charged with hydrogen. $10 \mathrm{~mm}$ and $25 \mathrm{~mm}$ strain gauge extensometers were attached to each specimen to measure its extension during mechanical loading.

The tensile specimens were cathodically hydrogen charged using an electrochemical cell with three electrodes in $1 \mathrm{M}$ of $\mathrm{NaCl}$ solution at $80^{\circ} \mathrm{C}$. A platinum wire was the working electrode, the saturated calomel was the reference electrode and the tensile specimen was used as the counter electrode. The current density was set at $7.7 \mathrm{~mA} / \mathrm{cm}^{2}$. The charging time was 1 week. The cell was de-aerated with nitrogen $\left(\mathrm{N}_{2}\right)$ for 30 minutes before charging. Subsequently, nitrogen gas was introduced in the sealed electrochemical cell for the entire duration of the charging, to reduce the oxygen level in the charging cell, which may corrode the sample. The potential in the specimen (working electrode) was measured against that of the reference electrode by means of a voltmeter. After charging, the samples were directly tested on the Instron load frame; the average duration of specimen exposure to atmosphere before the tensile test began, was 10 minutes.

The depth at which hydrogen diffuses into the specimen at the considered charging conditions was estimated using equation 1 .

$$
\mathrm{x}=\sqrt{2 \mathrm{Dt}}
$$

where:

$\mathrm{x}$, is the distance from the surface of the sample, $\mathrm{t}$, is the charging time and $\mathrm{D}$, is the hydrogen diffusion coefficient of a precipitation hardening alloy 718 [19], according to equation 2 :

$$
\mathrm{D}=6.8 \times 10^{-7} \exp \left(-\frac{49.5 \times 10^{3}}{\mathrm{RT}}\right)
$$

where:

$\mathrm{R}$, is the gas constant

$\mathrm{T}$, is the temperature in Kelvin $(\mathrm{K})$

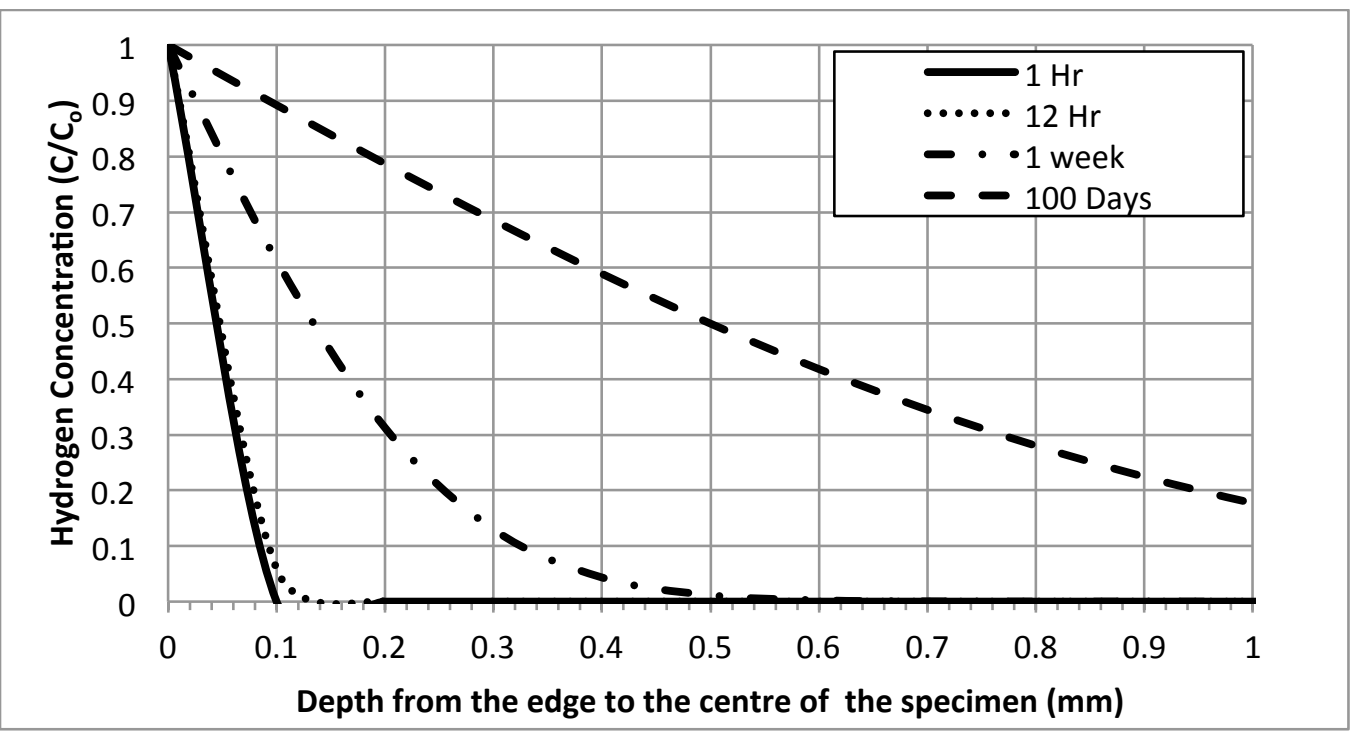

Figure 1: Hydrogen diffusion profiles for different times at $80^{\circ} \mathrm{C}(1 \mathrm{Hr}, 12 \mathrm{Hr}, 1$ week, 100 days $)$. 
Hydrogen diffusion profiles, as a function of charging time, are reported in Figure 1. According to the calculations made at the considered charging conditions, hydrogen needs approximately 100 days to reach the centre of the specimen. Due to time constraints, it was decided to charge the specimens with hydrogen for seven days. After this time, hydrogen is expected to reach up to $\sim 500 \mu \mathrm{m}$ from the specimen edge for all conditions. It is important to highlight that since fracture initiates from the region near the surface of the specimen, it is the hydrogen concentration in the near surface region that is most important.

\section{Results}

\subsection{Microstructural analysis of alloy 718}

SEM surface images of the examined conditions indicated that they all had approximately equiaxed grains. In addition, the images show clear evidence of annealing twins. These were observed in both small and large grains. The average grain sizes of the four heat treatments measured by linear intercept method were in the range of 66-78 $\mu \mathrm{m}$ (ASTM No. 4-4.5) [28], indicated that there was only a small amount of grain growth due to the additional solution annealing and age hardening heat treatments. The average grain size of the as received AER HT was $\sim 66 \mu \mathrm{m}$. The low band, high band and oil and gas heat treatments had an average grain size of $\sim 75 \mu \mathrm{m}, \sim 78 \mu \mathrm{m}$ and $\sim 72 \mu \mathrm{m}$, respectively.

EDS analysis was carried out to investigate the chemical composition of the MC type carbides and MN type nitrides ( $\mathrm{M}$ stands for metal, $\mathrm{C}$ stands for carbide and $\mathrm{N}$ stands for nitride) in the microstructure of the as-received (aerospace) condition, as shown in Figure 2(a) and (b). The shape and type of these carbides depend on the alloy composition, the process manufacturing conditions and heat treatment employed [2]. In many cases, $\mathrm{MC}$ and $\mathrm{MN}$ carbonitrides coexist. The carbides are usually characterized by coarse, blocky or rounded, irregular and discontinuous morphology [3,29]. In superalloy 718 the MC carbides and MN nitrides are rich in $\mathrm{Ti}$ or $\mathrm{Nb}$, forming $\mathrm{TiN}$ and $\mathrm{NbC}$. Carbonitrides are found primarily at grain boundaries, but they can also be found in the grain interiors. No other type of carbide was observed after any of the heat treatments.

Figure 2(b), shows blocky TiN, approximately $20 \mu \mathrm{m}$ in width, found in the as-received AER $\mathrm{HT}$, surrounded by smaller round shaped carbides rich in $\mathrm{Nb}$. Ti nitrides appear dark grey and $\mathrm{Nb}$ carbides appear light grey. It is clearly shown that the Ti nitrides and $\mathrm{Nb}$ carbides form from the melt, since they appeared in all conditions and were not sensitive to the applied heat treatment [2,3]. Carbide stringers were also observed in all heat treatments (LB HT, HB HT, AER HT and O\&G HT), as shown in Figure 2(c). Stringers of NbC align themselves continuously along the grain boundaries of the alloy. The width of these stringers varies from 1 to $15 \mu \mathrm{m}$. 

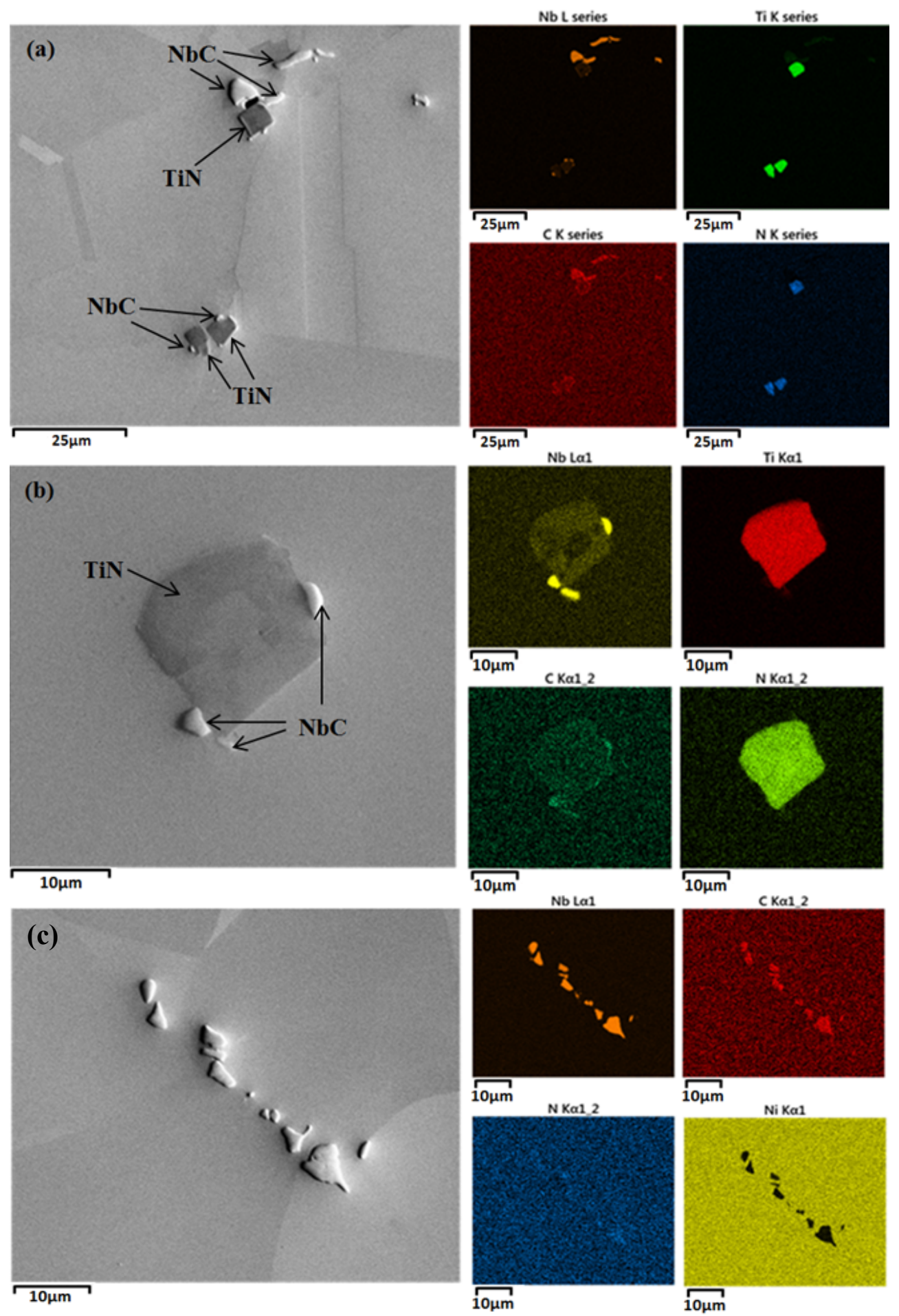

Figure 2: (a) and (b) MC type and MN type nitride morphology in alloy 718. (c) Carbide stringers.

\subsubsection{Aerospace heat treatment (AER HT)}

SEM images for material in the aerospace heat treatment condition are shown in Figure 3(a)(c). At low magnifications, the microstructure contained coarse titanium and niobium nitrides $((\mathrm{Ti}, \mathrm{Nb}) \mathrm{N})$ of approximately $10-20 \mu \mathrm{m}$ in length, and smaller carbides $((\mathrm{Ti}, \mathrm{Nb}) \mathrm{C})$ with a length of $5-10 \mu \mathrm{m}$.

Higher magnification SEM micrographs revealed intergranular $\delta\left(\mathrm{Ni}_{3} \mathrm{Nb}\right)$ phase in the aerospace HT (Figure 3(b)-(d)). However, most boundaries were free from $\delta$ phase precipitation. The platelet $\delta$ phase particles had a width of $15-40 \mathrm{~nm}$. 
Figure 3(b) illustrates $\gamma^{\prime}$ (spherical black dots) and $\gamma^{\prime \prime}$ (white disc-shaped particles) precipitates. As for the case of the O\&G HT, there is precipitate free zone depleted of the strengthening precipitates $\gamma^{\prime \prime}$ around the intergranular $\delta$ needles. The precipitate free zone around the $\delta$ phase was measured to have a width of $60-80 \mathrm{~nm}$.

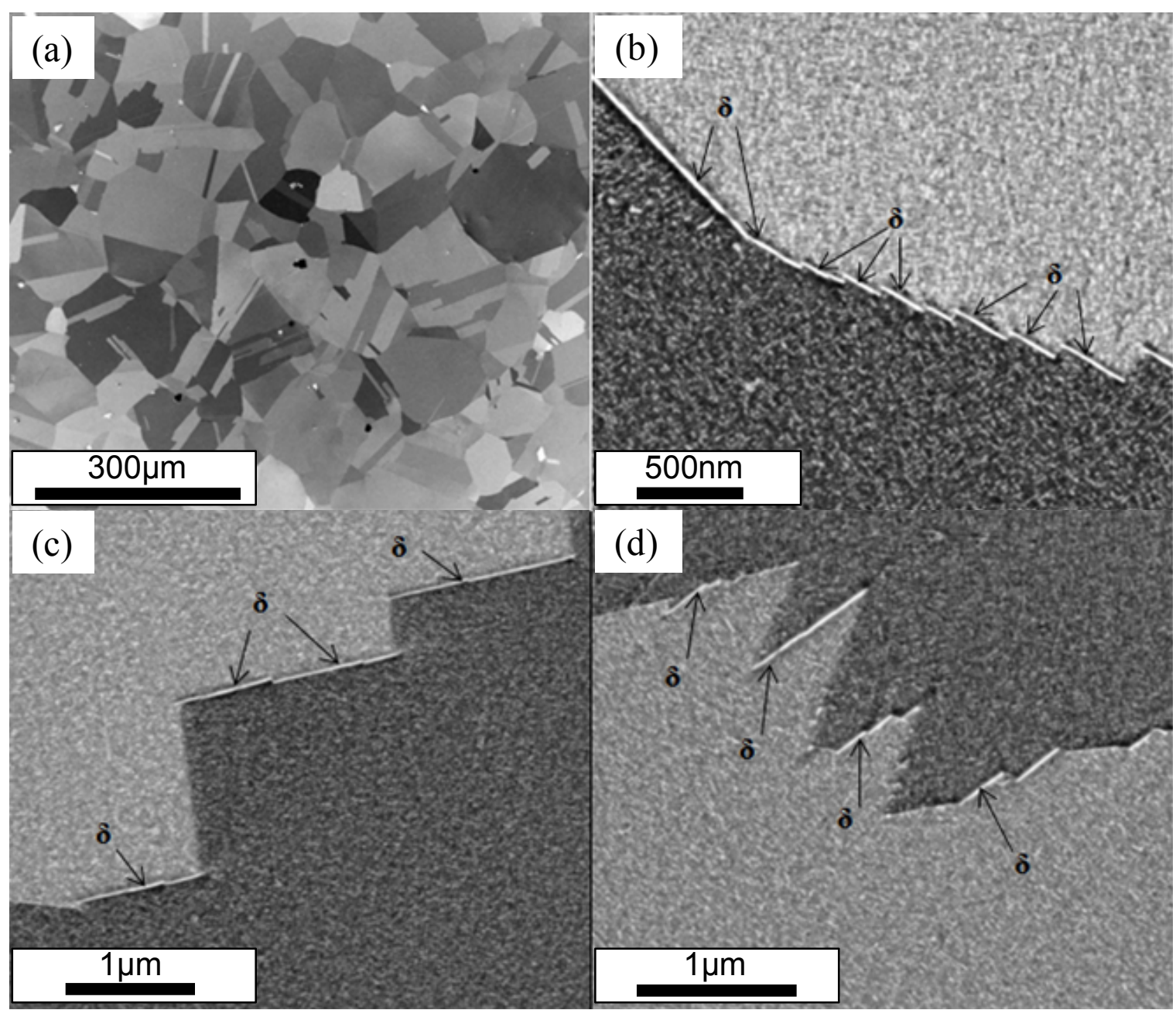

Figure 3: Backscatter SEM micrographs of the aerospace HT: (a) sample at low magnification (350x), (b)-(c)-(d) $\gamma^{\prime}, \gamma^{\prime \prime}$ and $\delta$ precipitates in the aerospace $H T$ at different locations.

\subsubsection{Oil and gas heat treatment (O\&G HT)}

Figure 4(a)-(d) show SEM micrographs of the oil and gas HT specimen. The strengthening phases $\gamma^{\prime}$ and $\gamma^{\prime \prime}$ were observed in the sample (Figure 4(a), (b)). Intergranular $\delta-\left(\mathrm{Ni}_{3} \mathrm{Nb}\right)$ phase was also observed in the oil and gas heat treatment (Figure 4(b)-(d)). The width of $\delta$ needles was measured as $30-40 \mathrm{~nm}$. The majority of the $\mathrm{Ni}_{3} \mathrm{Nb}$ phase can be detected at serrated grain boundaries, as shown in Figure 4(c) and (d). According to previous studies [30], the precipitation and growth of $\delta$ phase during any heat treatment below the $\delta$ solvus is responsible for serrated grain boundaries in the alloy. Ping et al. [31] also concluded that the zigzag-like morphology is also associated with the presence of $\gamma^{\prime \prime}$ precipitates at grain boundaries, since at high temperatures above $650^{\circ} \mathrm{C}$ these transform to the stable $\delta$ phase.

Depletion of $\gamma^{\prime \prime}$ precipitates is observed around the platelet $\delta$ phase (Figure 4(b) and (c)). The depleted zone is around $80-100 \mathrm{~nm}$ at each side of the grain boundary. 


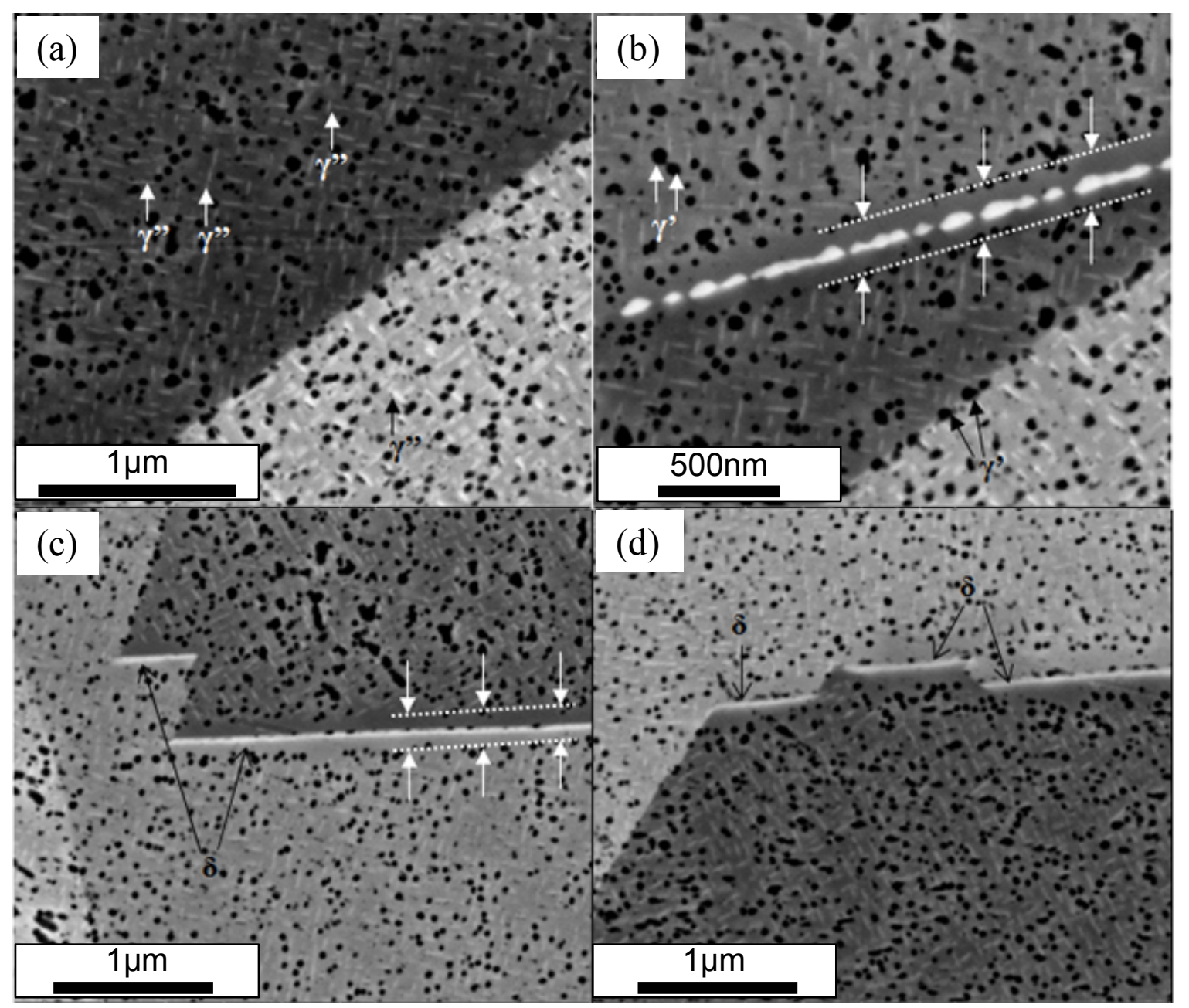

Figure 4: Backscatter SEM micrographs of the oil and gas HT: (a) $\gamma^{\prime}$ and $\gamma^{\prime \prime}$ precipitates ( $\delta$ free grain boundary), (b)(c)-(d) $\gamma^{\prime}, \gamma^{\prime \prime}$ and intergranular $\delta$ precipitates at different locations.

\subsubsection{Low band heat treatment (LB HT)}

Results from scanning electron microscopy observations of low band heat treated 718 specimens are presented in Figure 5(a)-(d) at different locations and magnifications.

As observed in these micrographs, grain boundaries were clean from platelet $\delta$ phase precipitation, and the second phase on the grain boundaries consisted mainly of TiN and NbC. It was observed that there was a higher concentration of carbonitrides along grain boundaries in the LB metallurgical state compared to the aerospace and the oil and gas heat treatment. $\mathrm{NbC}$ are shown in Figure 5(a), (b) and (c). Several positions within the matrix have been checked at high magnification, with no evidence of $\delta$ phase precipitation. Figure 5(d) shows the $\gamma^{\prime}$ and $\gamma^{\prime \prime}$ strengthening phases. $\gamma^{\prime}$-precipitates are again seen as black dots within the matrix, where $\gamma^{\prime \prime}$ precipitates are the white disc shaped particles. 


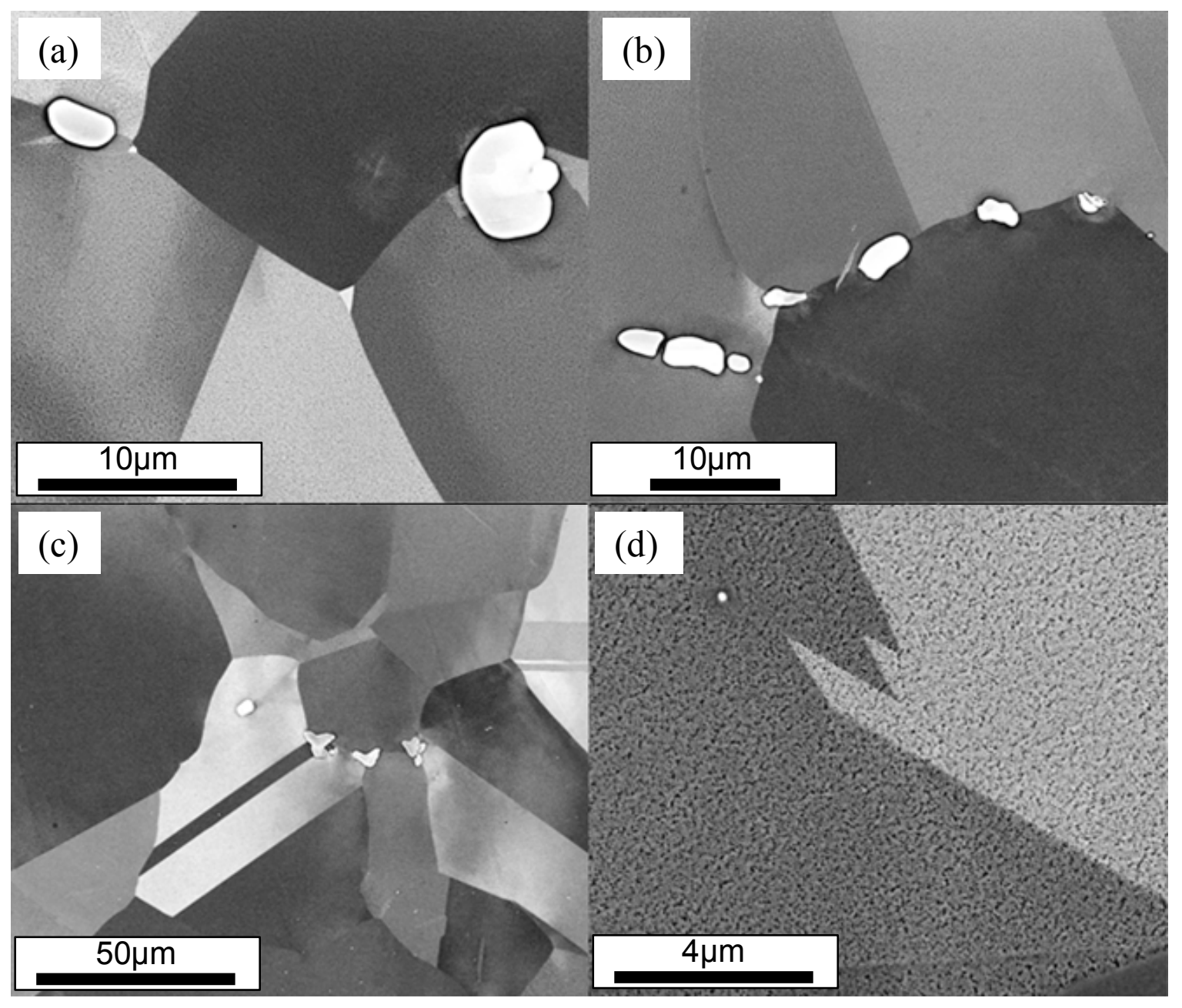

Figure 5: SEM backscatter micrographs of alloy 718 LB metallurgical state; (a) $\delta$ free grain boundaries, (b) Higher concentration of $\mathrm{Nb}$ - nitrides inclusions on or near the GB, (c) $\delta$ free GBs (2000x), (d) magnification image showing.

\subsubsection{High band heat treatment (HB HT)}

The SEM micrographs of the high band (HB) metallurgical state are shown in Figure 6(a)-(d). The HB samples contained a large number of carbonitride inclusions and carbide stringers (Figure 6(a)). High magnification SEM micrographs (Figure 6(b)-(d)) showed intergranular platelet $\delta$ phase. Although this phase exists in this metallurgical state, most grain boundaries were once again free of $\delta$ phase. The amount of $\delta$ phase was significantly reduced compared to the aerospace and oil and gas heat treatments. $\delta$-needles in this heat treatment are much finer, with a thickness between $10-15 \mathrm{~nm}$. The width of the precipitate free zone around the platelet $\delta$ was also reduced.

The HB heat treatment also contains $\gamma^{\prime}$ and $\gamma^{\prime \prime}$ precipitates. The strengthening phases were observed in the high magnification images, as shown in Figure 6(b)-(d). MC carbides were also observed at the grain boundaries. 


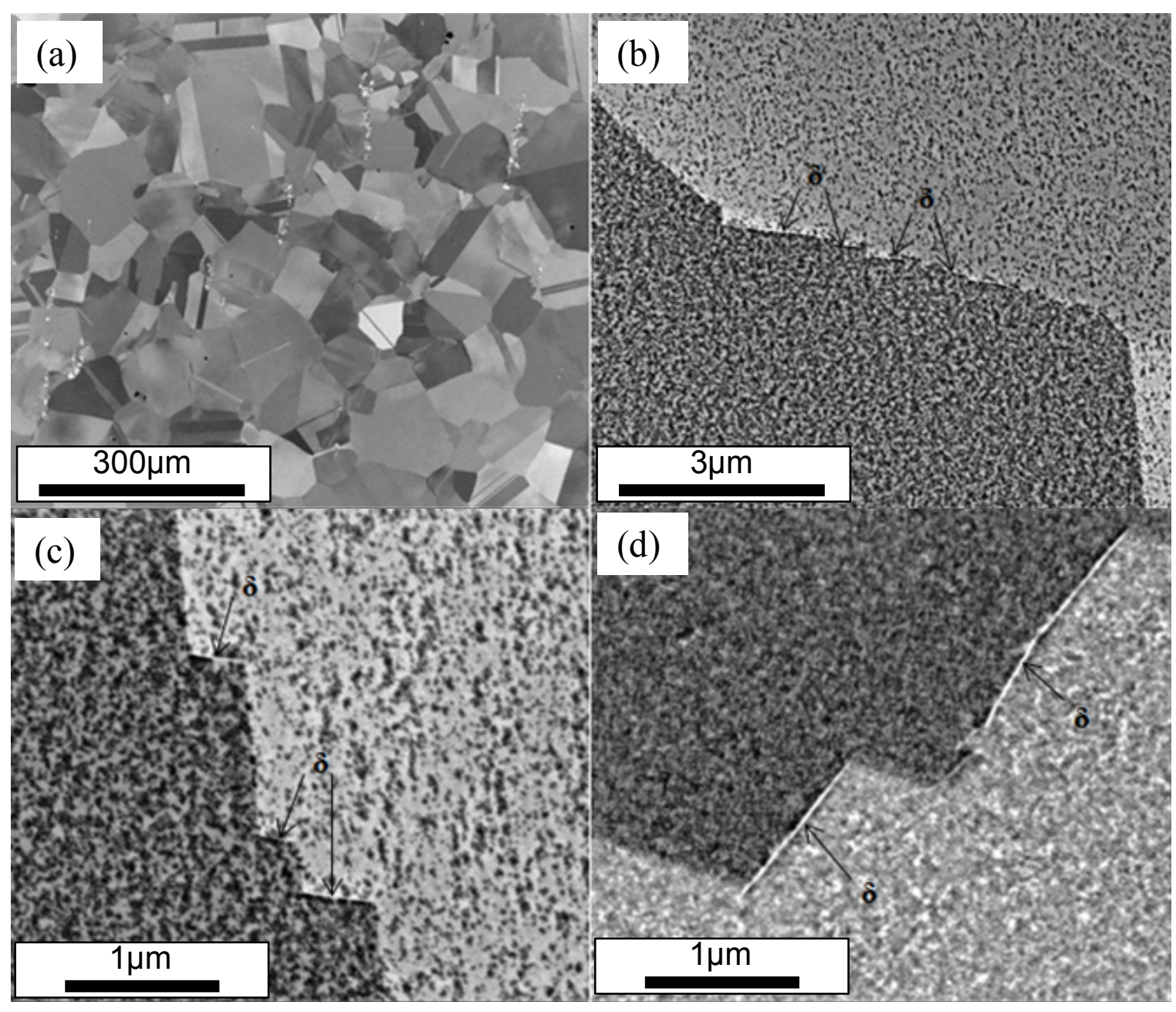

Figure 6: SEM backscatter micrographs of alloy $718 \mathrm{HB}$ metallurgical state; (a) low magnification image revealing high concentration of $\mathrm{NbC}$ inclusions $(350 \mathrm{x})$, (b)-(35000x)-(c) (80000x)-(d) (80000x), intergranular platelet $\delta$ phase from different from different locations.

\subsection{Effect of heat treatments on the hardness}

Figure 7 shows the hardness results of all four heat treatment conditions of alloy 718 . The average microhardness data were obtained from at least 10 measurements of the $10 \mathrm{~mm} \mathrm{x}$ $10 \mathrm{~mm}$ area of each sample.

The results showed that the oil and gas sample is softer than the two step aging LB, HB and AER heat treatments. The average hardness of the specimen was $362 \pm 5 \mathrm{HV}$. The average hardness obtained from the low band aging sample was $420 \pm 6 \mathrm{HV}$. The average hardness value of the low band heat treatment was $18 \mathrm{HV}$ lower than that obtained in the two step aerospace sample, which has a hardness of $438 \pm 5 \mathrm{HV}$.

The high band aging sample has an average hardness of $440 \pm 5 \mathrm{HV}$. Therefore, the high band HT has almost identical hardness to the aerospace sample. 


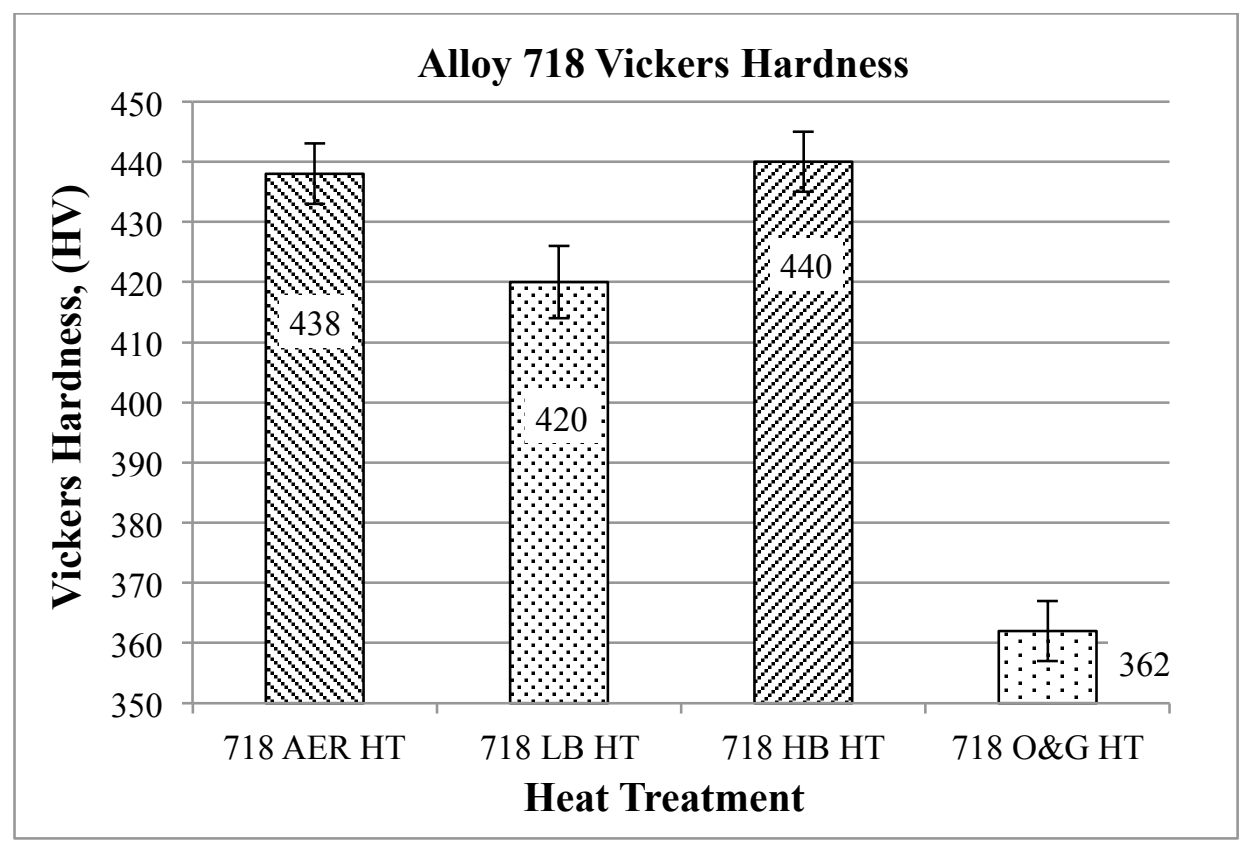

Figure 7: Comparison of hardness values obtained for the different microstructures.

\subsection{Tensile properties}

Figure 8 shows the tensile properties of the non-charged and pre-charged specimens for each examined condition.

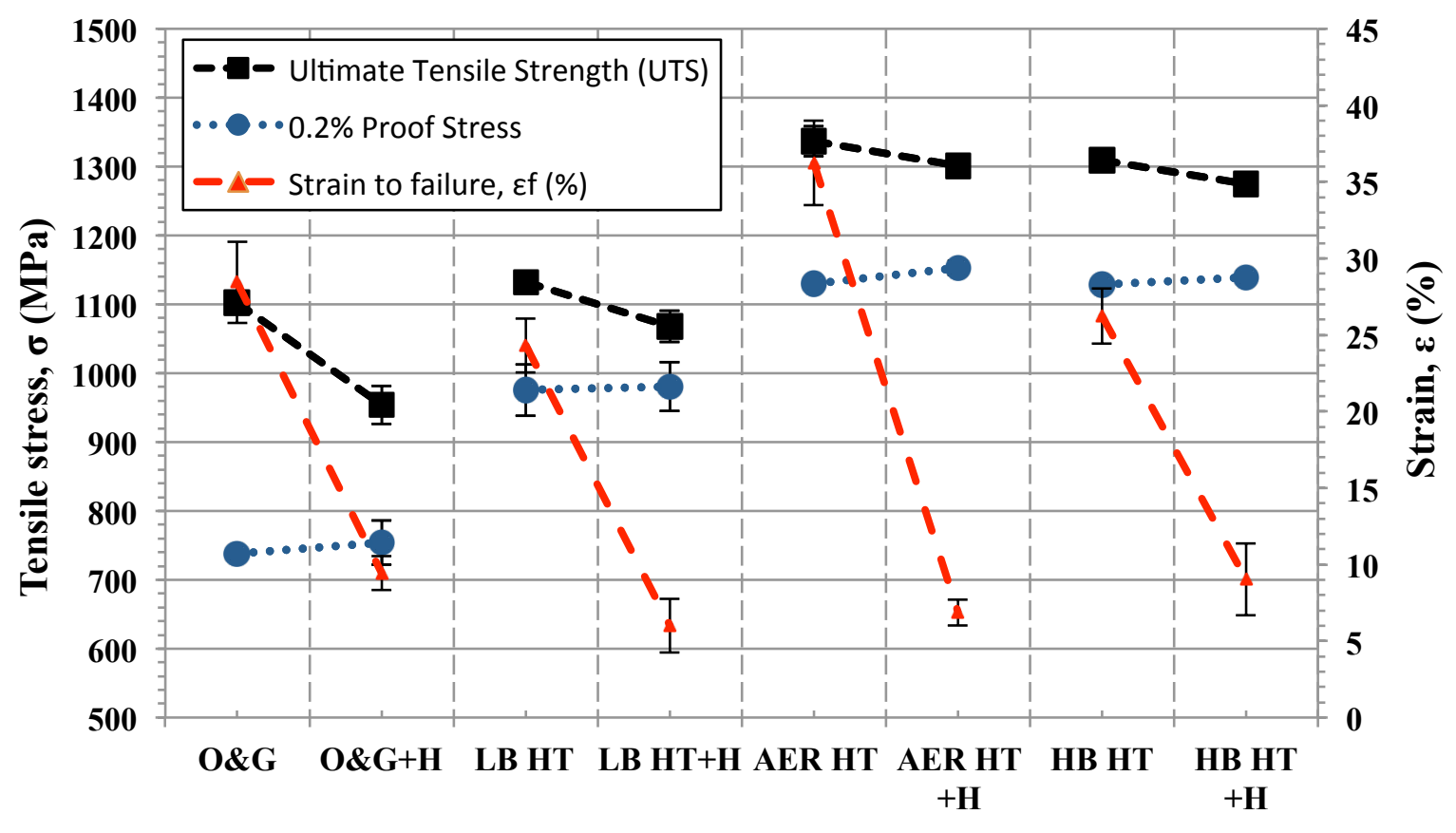

Figure 8: Tensile testing results (non-charged and pre-charged with Hydrogen) of the examined microstructural conditions as per table 2 .

Several points regarding the results are noteworthy. First, for all heat treatments, hydrogen decreases the ultimate tensile strength and the ductility, whereas the $0.2 \%$ proof stress was slightly increased (by up to $\sim 2 \%$ at most). Second, in the uncharged samples, the highest ductility was achieved by the AER HT, which has also the highest value of strength (UTS and $0.2 \%$ proof stress) in both charged and uncharged states. This is uncommon, since an inverse relationship between strength and ductility is usually expected $[13,32]$. However, the strain to 
failure value of AER HT samples decreased most strongly after hydrogen pre-charging, from an average value of $36 \%$ to an average value of $7 \%$.

The O\&G HT has the lowest UTS and $0.2 \%$ proof stress of the four conditions in both noncharged and pre-charged states, whereas its ductility is the highest and the second highest in the charged and uncharged condition, respectively.

The LB HT, with the $\delta$-free microstructure, has the second lowest UTS and $0.2 \%$ proof stress and the lowest strain to failure values of all conditions in both hydrogen charged and uncharged samples.

Finally, the HB HT, with a longer aging treatment than the LB HT, revealed the second highest UTS and $0.2 \%$ proof stress from the charged and uncharged samples. However, it has similar strain to failure value to the O\&G HT in the hydrogen charge state, around $9 \%$.

\subsection{Fractography}

The fracture surfaces and the longitudinal sections of the tensile specimens were examined using scanning electron microscopy to reveal the hydrogen embrittlement mode in the microstructures produced by the four heat treatment conditions.

On macroscopic scale, all uncharged specimens in all conditions showed a cup-cone fracture after severe necking. The hydrogen charged samples all showed a brittle fracture with minimal plastic deformation and cracks running close to perpendicular to the applied force.

At the microscopic level, the non-charged samples showed typical ductile dimple fracture surfaces as shown in Figure 9(a)-(d). The surfaces of all uncharged specimens consist of many dimples, which grew under tensile load and coalesced, until dimple rupture occurred. This fracture mode is known as microvoid coalescence (MVC). Cracked carbonitrides were also observed in some of these dimples. 


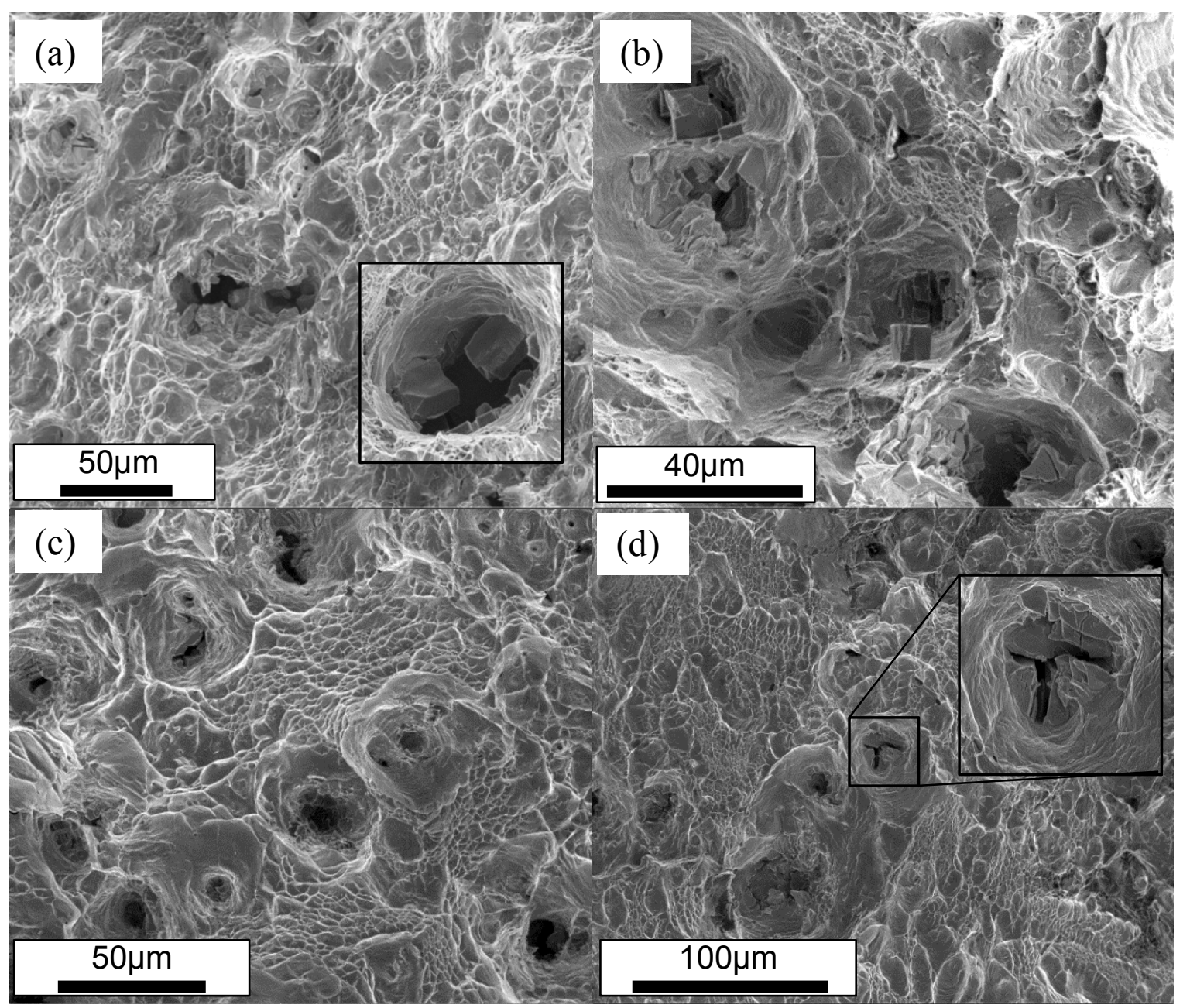

Figure 9: SEM secondary electron images of the tensile fracture surfaces of the non-charged specimens. (a) O\&G HT, (b) AER HT, (c) LB HT, (d) HB HT.

On the other hand, the hydrogen pre-charged samples revealed a brittle, mixed brittle (indicated by arrows), and ductile fracture patterns (Figure 10(a)-(d)). A brittle ring of approximately $350-450 \mu \mathrm{m}$ from the edge towards the centre of the tensile specimens was observed (Figure 10(a)), which is consistent with the hydrogen diffusion depth calculations performed prior the tests (see Figure 1). As expected, the central regions of the H-charged samples showed a typical ductile fracture behaviour by MVC similar to this observed in noncharged specimens, since hydrogen did not penetrate that region. Further, all pre-charged specimens displayed a brittle intergranular mode of fracture. Secondary intergranular cracks were observed in all conditions (indicated in circles), as well as cleavage facets along defined planes and cleavage-like step facetted fracture modes. 


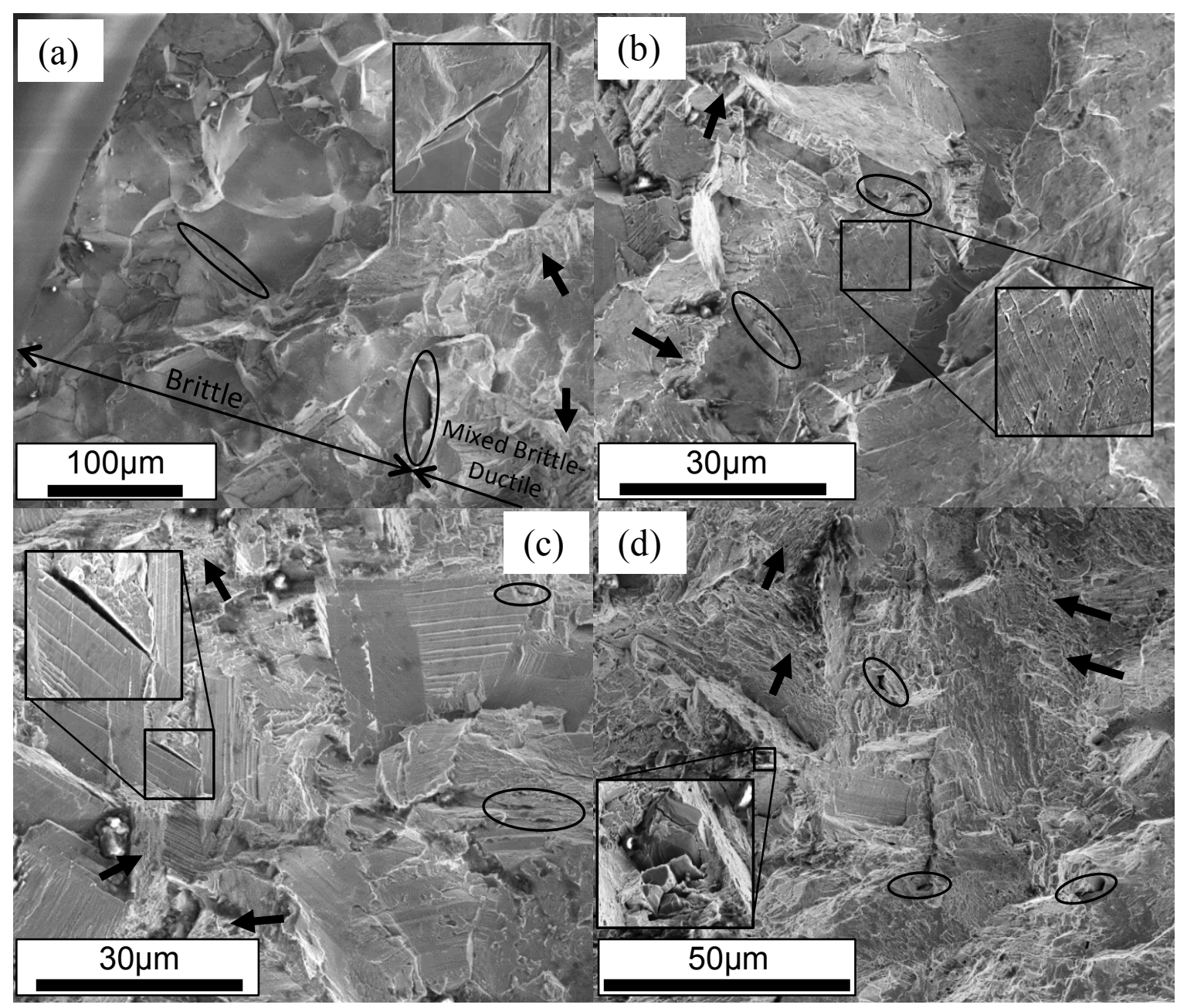

Figure 10: SEM secondary electron fractography images of pre-charged specimens. (a) O\&G HT+H, (b) AER HT + H, (c) LB HT+H, (d) HB HT+H.

As shown in Figure 11(a)-(d), intergranular and transgranular microvoids/microcracks were observed within the brittle ring. Voids are forming along and at the intersection of slip bands, at the grain boundaries and second phase particles (Figure 11(a)-(d)). No microvoids or microcracks were found in non-charged specimens or at the hydrogen-free areas in the middle of the pre-charged samples. 


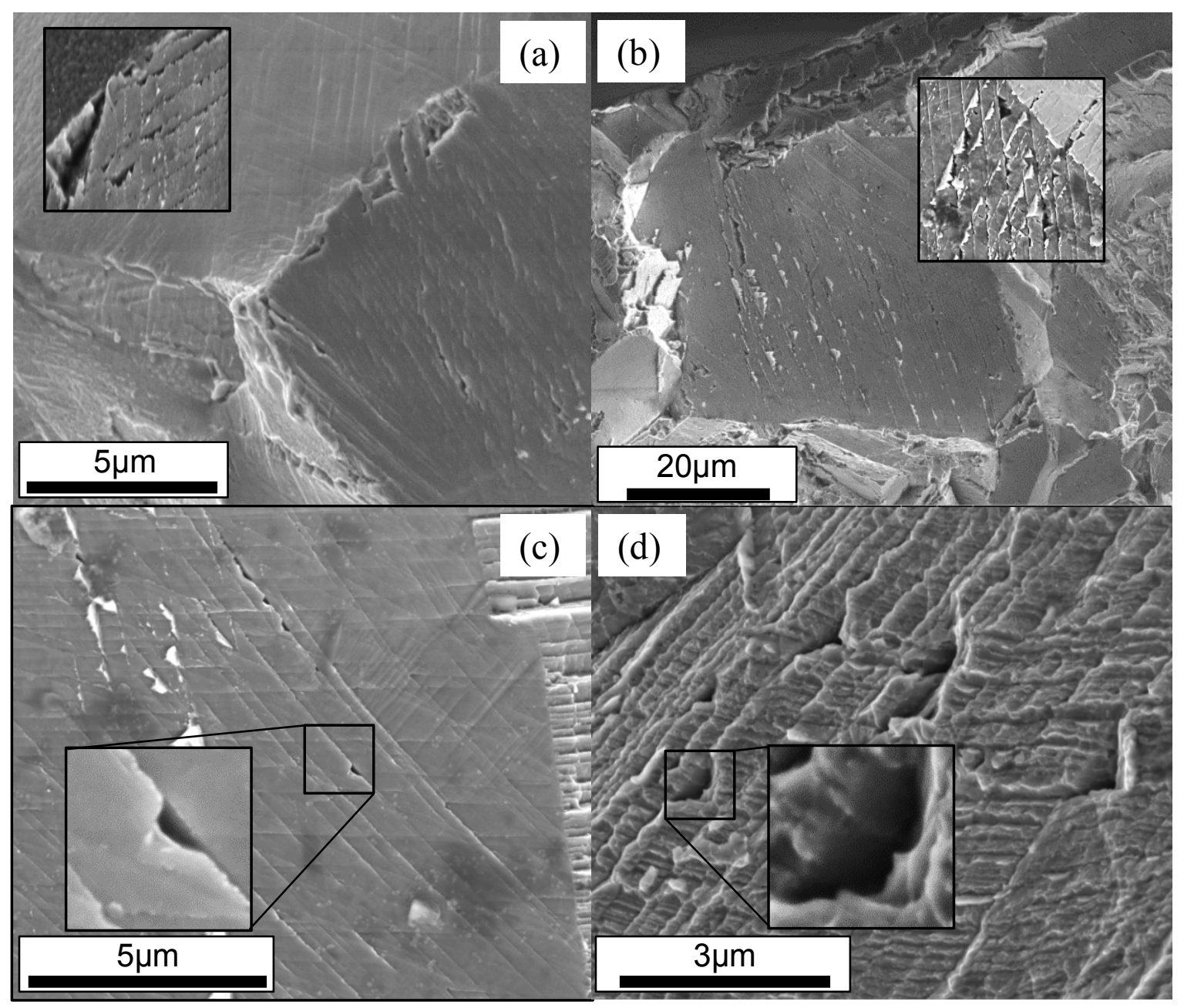

Figure 11: Intergranular and transgranular microvoids/microcracks on hydrogen pre-charged fracture surface (Secondary electron micrographs). (a) O\&G HT+H, (b) AER HT+H, (c) LB HT+H, (d) HB HT+H.

Figure 12 shows backscattered electron micrographs of the failed gauge length for a longitudinal section of charged and non-charged specimens. As shown in the images, the majority of the carbonitrides in both non-charged and hydrogen pre-charged conditions have cracked. Figure 12 (d)-(e) show that in the presence of hydrogen cracks initiated and propagated within the matrix from cracked carbonitrides found on the grain boundaries. On the other hand, crack blunting was observed in the non-charged samples (Figure 12 (a), (b) and (c)), as none of these cracks have propagated from the carbides into the matrix.

As illustrated in Figure 13, and annotated by white arrows, highly deformed transgranular fracture surfaces along the secondary cracks were observed in all hydrogen pre-charged conditions. The majority of secondary cracks propagated along grain boundaries. Transgranular cracking is also occasionally observed in SEM images of longitudinal sections, especially along slip bands, however, the cracks always tend to return to the nearest grain boundary. Microcracks were also observed running along, and at the intersection of, slip bands in all pre-charged specimens. Lastly, grain boundaries decorated with coarse $\delta$ phase needles appeared to be crack initiation points (Figure 13(c)). 


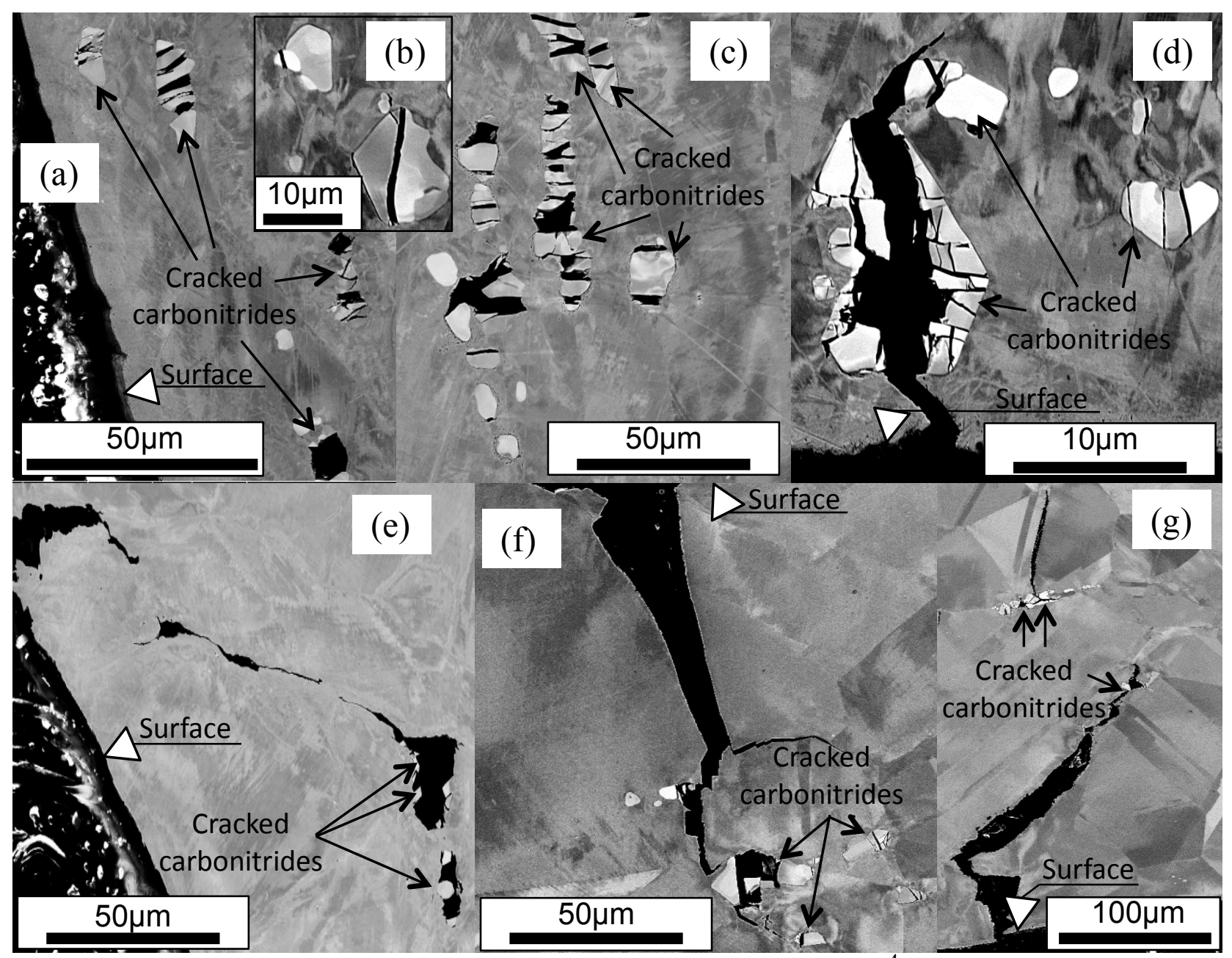

Figure 12: Cracked carbonitrides after testing the specimens in a strain rate of $3.33 \times 10^{-4} / \mathrm{s}$. (a) Non-charged LB HT, (b) Non-charged O\&G HT, (c) Non-charged HB HT, (d) Pre-charged HB HT, (e) Pre-charged LB HT, (f) Pre-charged O\&G HT, (g) Pre-charged AER HT. 


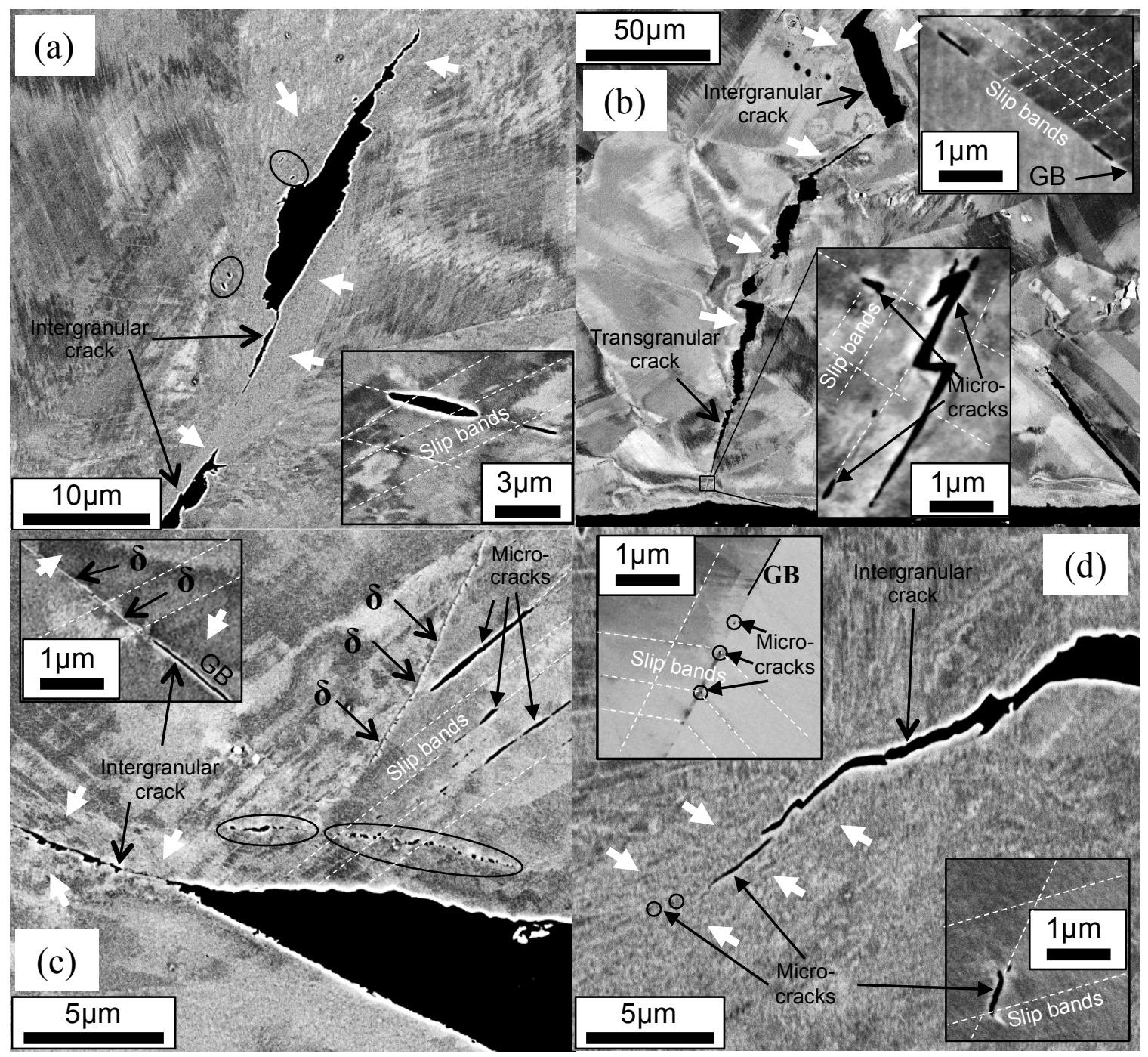

Figure 13: Backscatter SEM micrographs of longitudinal section through the fracture surface. (a) O\&G HT+H, (b) 718 HB HT+H, (c) 718 AER HT+H, (d) 718 LB HT+H

\section{Discussion}

\subsection{Precipitation phases, hardness evolution and mechanical properties}

Scanning Electron Microscopy has revealed that the strengthening precipitates that form in alloy 718 during a single or a two-step heat treatment, are a mixture of intragranular $\gamma^{\prime \prime}$ and $\gamma^{\prime}$ phases. Ti-nitrides, $\mathrm{Nb}$-carbides and carbide stringers were also observed in all heat treatment conditions.

The oil and gas heat treatment led to the formation of a non-continuous intergranular $\delta$ phase on some of its grain boundaries. The O\&G single heat treatment led to coarser $\gamma^{\prime}, \gamma^{\prime \prime}$ and $\delta$ precipitates compared to the other examined samples.

Intergranular $\delta$ phase was also observed in the two-step aerospace (AER) and high band (HB) heat treatments. The 718 HB HT produced finer $\delta$ phase than the AER HT. Solution heat treating the alloy below $\delta$ solvus, as the case of the AER HT, promotes the precipitation of grain boundary $\delta$ phase, which then grows during the first precipitation hardening step above $650^{\circ} \mathrm{C}$. At this stage of the aging treatment, three phenomena occur:

(a) $\gamma^{\prime \prime}$ and $\gamma^{\prime}$ phases form

(b) a fraction of the precipitated $\gamma^{\prime \prime}$, as the metastable phase, dissolves in the matrix to form the stable $\delta$ phase 
(c) the existing $\delta$ phase gets coarser

Since the solution heat treatment of the HB HT at $1040^{\circ} \mathrm{C}$ completely dissolves the $\delta$ phase, the formation of $\delta$ during ageing requires first nucleation of new precipitates followed by their growth. As a result, the amount of $\delta$ phase was significantly reduced and the needles have a finer width than the AER HT.

The SEM investigation of the low band HT revealed a $\delta$-free grain boundary microstructure. The strengthening phases $\gamma^{\prime}$ and $\gamma^{\prime \prime}$ were observed in the matrix. A higher concentration of carbides $(\mathrm{NbC})$ and carbide stringers were observed in the microstructure. Carbide inclusions were observed in higher quantities than in the other microstructural states because the lack of $\delta$ phase due to the short ageing time $\left(4\right.$ hours at $712^{\circ} \mathrm{C}$ ) means that there is more carbide forming solute $(\mathrm{Nb})$ available in the matrix.

Intergranular $\delta$ phase formation leads to precipitation free zones (PFZ) around the $\delta$-needles, which are denuded of $\gamma^{\prime \prime}$ hardening precipitates. This effect is more pronounced in heat treatments with coarse $\delta$ phase precipitates, like the O\&G and AER conditions.

As expected, the measured strength values in the non-charged samples were consistent with the hardness values, as well as with the microstructural examination. Non-charged AER HT and HB HT gave the highest strength, commensurate with the high number density of dispersed $\gamma^{\prime}, \gamma^{\prime \prime}$ and $\delta$ phase. The single-step uncharged O\&G HT gave the lowest strength, consistent with the microstructure being overaged compared to the other metallurgical states. Uncharged LB HT which has a finely dispersed microstructure of $\gamma^{\prime}$ and $\gamma^{\prime \prime}$ (and no $\delta$ ) due to the shorter precipitation hardening treatment compared to AER and HB heat treatments, gave an intermediate strength value.

Pre-charged hydrogen had a significant impact on the strength, ductility and fracture mode of all heat treatments. The most susceptible heat treatment to hydrogen embrittlement in terms of ductility reduction was AER HT ( $\varepsilon_{\mathrm{f}}$ ratio Pre-charged/Non-charged $\%=19.1 \%$ ), followed by LB HT $\left(\varepsilon_{\mathrm{f}}\right.$ ratio $\left.\%=24.7 \%\right)$, O\&G HT $\left(\varepsilon_{\mathrm{f}}\right.$ ratio $\left.\%=33.1 \%\right)$ and $\mathrm{HB}$ HT $\left(\varepsilon_{\mathrm{f}}\right.$ ratio $\left.\%=34.4 \%\right)$.

The different precipitate phases formed during the different aging heat treatments strongly influence the resistance to hydrogen embrittlement, but this cannot be attributed uniquely to only one particular phase (e.g. $\delta$-phase). The AER HT, which has the highest strength value, medium sized $\delta$ phase on some of its grain boundaries, and finely dispersed $\gamma^{\prime}$ and $\gamma^{\prime \prime}$ was the worst case. LB HT with a $\delta$-phase-free microstructure, the finest dispersed $\gamma^{\prime}$ and $\gamma^{\prime \prime}$ also experienced a large reduction in ductility. On the other hand, the HB HT with finely dispersed $\gamma^{\prime}, \gamma^{\prime \prime}, \delta$ phases, and high tensile strength value was least embrittled by hydrogen. The O\&G HT with the coarsest $\gamma^{\prime}, \gamma^{\prime \prime}$ and $\delta$ phases but lowest strength value performed similarly.

Previous investigations have suggested $[6-8,13]$ that the tendency for hydrogen embrittlement is controlled by the fraction of $\delta$-phase. Whilst this is a contributory factor, this work shows a more complex situation. This is evidenced by the observation that the O\&G HT and HB HT $\delta$-phase containing microstructures show a lower loss of ductility with hydrogen, than the $\delta$ phase free microstructure produced by the LB HT. Another point of interest is the hardness value and strength of the HB HT. According to NACE specification MR0175 [4], the HB HT has a higher hardness value 40 Rockwell C; therefore it would not conform to the current standard for sour oilfield conditions. However, this investigation revealed that this heat treatment could produce a microstructural state that yields both higher strength and reduced loss of ductility when exposed to hydrogen. This emphasises that the simple hardness limit prescribed by the current standard does not necessarily lead to material in the optimum condition for its application. 


\subsection{The failure mechanism}

The fracture surface of all non-charged specimens was ductile, occurred through microvoid coalescence (MVC). Initiation is caused by cracking of carbonitrides, which was found in dimples, as shown in Figure 9(a)-(d). Therefore, the volume fraction, morphology and size of carbonitrides play an important role in determining fracture behaviour in alloy 718 .

The microstructure of all pre-charged samples is characterised by substantial slip band formation and highly localised deformation along the fracture surfaces, despite the microstructural differences among them. Nanovoids and microcracks were found to form along slip bands and grain boundaries (Figure 11 and Figure 13). Crack growth occurs by a microvoid coalescence process in both the grain boundaries (mainly) and along the slip bands (secondly) as shown in Figure 12 and Figure 13. These results are consistent with some aspects of the hydrogen enhanced localised plasticity (HELP) mechanism, and they were previously reported by other researchers [12,33-38]. However, direct evidence of enhanced dislocation motion at lower stresses due to hydrogen shielding, which is the underlying principle in the HELP mechanism, has not been obtained. Nanovoids formed at the intersection of slip bands and grain boundary interfaces (Figure 11 and Figure 13) are consistent with the Zener-Stroh and Cottrell crack initiation mechanisms [9,39-42].

\section{Conclusions}

Nickel alloy 718 was given four different heat treatments to develop different microstructural states, and the susceptibility of each of these states to hydrogen embrittlement was assessed. The heat treatments strongly influenced the nature and distribution of the precipitate phases observed. This, in turn, had a strong effect on the strength and ductility before and after hydrogen charging. As expected, a heat treatment that gives a high strength (as utilized in the aerospace industry) showed the highest loss in ductility with hydrogen. The standard oil and gas heat treatment showed a reduced tendency for hydrogen embrittlement, but an alternative heat treatment (HB-HT) gave even better ductility after charging, along with improved strength.

The fracture surface of all non-charged specimens was ductile, occurred through microvoid coalescence (MVC). Crack initiation is caused by cracking of carbonitrides which were found in dimples. Cracking in all pre-charged specimens occurs mainly on the grain boundaries, and secondly along slip bands, by MVC, despite the microstructural differences between them. The presence of grain boundary $\delta$-phase may assist the cracking when its morphology is coarse enough to initiate cracks during tensile testing. However, the loss of ductility on hydrogen charging is not uniquely controlled by $\delta$-phase, but is also influenced by other microstructural features. It has been demonstrated that microstructural states can be achieved that give both reduced hydrogen embrittlement and a higher strength level than achieved by the standard oil and gas heat treatment.

\section{Acknowledgements}

The author gratefully acknowledges the financial support of the Engineering and Physical Sciences Research Council (EPSRC) through the Sheffield/Manchester CDT (Advanced Metallic Systems) and BP's sponsorship through the BP International Centre of Advanced Materials (BP-ICAM), which made this research possible. 


\section{References:}

1. API Standard 6A718: Age-Hardened Nickel-Based Alloys for Oil and Gas Drilling and Production Equipment, 3rd Edition (2010).

2. R. C. Reed, The Superalloys:Fundamentals and Applications (Cambridge University Press, Cambridge, 2006).

3. M. J. Donachie and S. J. Donachie, Superalloys: A Technical Guide (ASM International, USA, 2002).

4. NACE International, NACE Standard MR0175-2003: Standard Material Requirements. Metals for Sulfide Stress Cracking and Stress Corrosion Cracking Resistance in Sour Oilfield Environments (NACE International, Houston, Texas, 2003).

5. M. C. Rezende, L. S. Araujo, S. B. Gabriel, D. S. dos Santos, and L. H. de Almeida, Int. J. Hydrogen Energy 40, 17075 (2015).

6. L. Liu, C. Lu, W. Ding, A. Hirose, and K. Kobayashi, J. Mater. Sci. Technol. 21, 256 (2005).

7. L. Liu, C. Zhai, C. Lu, W. Ding, A. Hirose, and K. F. Kobayashi, Corros. Sci. 47, 355 (2005).

8. S. Huizinga, B. Mcloughlin, W. E. Liek, J. G. De Jong, S. Global, and S. International, in Corros. 2003, NACE Int. Houston, Texas (2003), pp. 1-9.

9. L. Fournier, D. Delafosse, and T. Magnin, Mater. Sci. Eng. A 269, 111 (1999).

10. L. Foroni, G. Minore, and C. Malara, in Corros. 2014 (2014), pp. 1-15.

11. S. Jothi, S. V. Merzlikin, T. N. Croft, J. Andersson, and S. G. R. Brown, J. Alloys Compd. 664, 664 (2016).

12. Z. Zhang, G. Obasi, R. Morana, and M. Preuss, Acta Mater. 113, 272 (2016).

13. L. Liu, K. Tanaka, A. Hirose, and K. Kobayashi, Sci. Technol. Adv. Mater. 3, 335 (2002).

14. Z. Tarzimoghadam, M. Rohwerder, S. V. Merzlikin, A. Bashir, L. Yedra, S. Eswara, D. Ponge, and D. Raabe, Acta Mater. 109, 69 (2016).

15. R. Ayer, R. R. Mueller, J. Y. Koo, and M. Watkins, in Int. Offshore Polar Eng. Conf. Honolulu, Hawaii,USA (2003), pp. 75-82.

16. J. J. M. Jebaraj, D. J. Morrison, and I. I. Suni, Corros. Sci. 80, 517 (2014).

17. J. J. M. Jebaraj, D. J. Morrison, and I. I. Suni, Corros. 20141 (2014).

18. B. G. Pound, Evaluation of a Diffusion/trapping Model for Hydrogen Ingress in HighStrength Alloys (1990).

19. W. M. Robertson, Metall. Trans. A 8A, 1709 (1977).

20. F. Galliano, E. Andrieu, C. Blanc, J. M. Cloue, D. Connetable, and G. Odemer, Mater. Sci. Eng. A 611, 370 (2014).

21. B.G. Pound, Corros. Sci. 42, 1941 (2000).

22. S. Mannan, in NACE Corros. 2010 Conf. Expo (2010), pp. 1-15. 
23. J. R. Davis, ASM Specialty Handbook: Heat-Resistant Materials (ASM International, 1997).

24. R. B. Bhavsar, A. Collins, and S. Silverman, in Superalloys 718, 625, 706 Deriv. E.A. Loria Ed., TMS (2001), pp. 47-55.

25. A. Agnoli, M. Bernacki, R. E. Log, J. Franchet, J. Laigo, and N. Bozzolo, in 12th Int. Symp. Superalloys (2012), pp. 73-82.

26. S. Mahadevan and S. Nalawade, 7th Int. Symp. Superalloys 718 Deriv. 737 (2010).

27. NACE International, NACE Standard TM 0177-2005: Laboratory Testing of Metals for Resistance to Sulfide Stress Cracking and Stress Corrosion Cracking in H2S Environments (Houston, Texas, 2005).

28. ASTM E112-13 Standard, Standard Test Methods for Determining Average Grain Size (Conshohocken, PA, 2013).

29. A. Nowotnik, J. Sieniawski, and G. Mrówka-Nowotnik, J. Achiev. Mater. Manuf. Eng. 31, 275 (2008).

30. A.-C. Yeh, K.-W. Lu, C.-M. Kuo, H.-Y. Bor, and C.-N. Wei, Mater. Sci. Eng. A 530, 525 (2011).

31. D. H. Ping, Y. F. Gu, C. Y. Cui, and H. Harada, Mater. Sci. Eng. A 456, 99 (2007).

32. M. Moiz, The Influence of Grain Size on the Mechanical Properties of Inconel 718, Linkoping University, Sweden, 2013.

33. H. K. Eastman, J., Matsumoto, T., Narita, N., Heubaum, N., Birnbaum, Hydrog. Met. 397 (1981).

34. T. Matsumoto, J. Eastman, and H. K. Birnbaum, Scr. Metall. 15, 1033 (1981).

35. S. P. Lynch, NACE Int. Corros. 20071 (2007).

36. S. P. Lynch, in Gaseous Hydrog. Embrittlement Mater. Energy Technol. Probl. Its Characterisation Eff. Part. Alloy Classes (2012), pp. 274-346.

37. P. Sofronis and I. M. Robertson, AIP Conf. Proc. 837, 64 (2006).

38. P. Sofronis, Y. Liang, and N. Aravas, Eur. J. Mech. A/Solids 20, 857 (2001).

39. Z. M. Xiao, H. Fan, and Y. M. Suh, Acta Mech. 142, 133 (2000).

40. P. Sofronis and H. K. Birnbaum, J. Mech. Phys. Solids 43, 49 (1995).

41. G. R. Caskey, A Mechanism for Hydrogen-Induced Brittle Fracture of Austenitic Stainless Steels (Denver, Colorado, USA, 1978).

42. J. E. Angelo, N. R. Moody, and M. I. Baskes, Model. Simul. Mater. Sci. Eng. 3, 289 (1995). 